\title{
Severity of cognitive disability and Mental Health Court determinations about fitness to stand trial
}

Jesse T Young ${ }^{1,2,3}$, Fiona J Davis ${ }^{4,5}$, Simon Wardale ${ }^{4,6}$, Maria Vassos ${ }^{7,4,6}$, Kate van Dooren ${ }^{8}$, Karen Nankervis ${ }^{4,7}$, Nicholas G Lennox ${ }^{8}$

${ }^{1}$ Melbourne School of Population and Global Health, The University of Melbourne, Parkville, VIC, 3010, Australia

${ }^{2}$ Centre for Health Services Research, School of Population and Global Health, The University of Western Australia, Perth, WA, 6009, Australia

${ }^{3}$ National Drug Research Institute, Curtin University, Perth, WA, 6008, Australia

${ }^{4}$ Centre of Excellence in Clinical Innovation and Behaviour Support, Department of Communities,

Child Safety and Disability Services, Queensland, Brisbane, QLD, 4000, Australia

${ }^{5}$ Lifestyle Solutions, Beenleigh, QLD, 4207, Australia

${ }^{6}$ Endeavour Foundation, Cannon Hill, QLD, 4170, Australia

${ }^{7}$ School of Education, University of Queensland, Brisbane, QLD, 4072, Australia

${ }^{8}$ Queensland Centre for Intellectual and Developmental Disability, Mater Research Institute-UQ, University of Queensland, South Brisbane, QLD, 4101, Australia

Word count (Introduction - Conclusion): 3626; Abstract: 225;

Number of pages: 22; Number of tables: 2; Number of figures: 0

Corresponding Author:

Mr Jesse T Young

The University of Melbourne

Level 4, 207 Bouverie Street, Carlton, VIC, 3010, Australia

Tel: +61 38344 4413; Fax: +61 393481174

Email: jesse.young@unimelb.edu.au

Note: This is the pre-peer reviewed version of the following article Young JT, Davis FJ, Wardale S, Vassos M, van Dooren K, Nankervis K, Lennox N G. Severity of cognitive disability and Mental Health Court determinations about fitness to stand trial. Journal of Intellectual Disability Research. 2018; 62(2): 126-139., which has been published in final form at https://doi.org/10.1111/jir.12468. This article may be used for non-commercial purposes in accordance with Wiley Terms and Conditions for Self-Archiving. 


\section{ABSTRACT}

Background: Little is known about the socio-demographic, clinical and legal determinants of mental health court decisions of unsoundness of mind and unfitness to stand trial for people with cognitive disability. We aimed to estimate the association between severity of cognitive disability and mental health court determinations of unsoundness or unfitness and describe the socio-demographic, clinical and legal factors that predict these determinations.

Methods: Case file data was extracted on 92 individuals who had a criminal case referred to the Queensland Mental Health Court between 1 January 2013 and 31 December 2014 due to cognitive disability. We fit a modified multivariable Poisson regression model to estimate the association between severity of cognitive impairment and mental health court determination, controlling for socio-demographic, clinical and legal factors.

Results: Adjusting for covariate effects, severity of cognitive impairment was positively associated with being found unfit to stand trial [adjusted prevalence risk ratio $[(A P R R)=1.57$; $95 \% \mathrm{Cl}: 1.07,2.33 ; \mathrm{p}=0.023]$ and comorbid psychotic disorder predicted an increased risk of being found unsound of mind at the time of offence (APRR=3.63; $95 \% \mathrm{Cl}: 1.38,9.54$; $\mathrm{p}=0.009$ ) by the Queensland Mental Health Court.

Conclusions: Severity of cognitive disability is associated with determinations of unfitness but does not predict determinations of unsoundness in the Queensland Mental Health Court. Psychiatric assessments of cognitive impairment play a pivotal role in mental health court determinations for people with cognitive disability.

Key Words: Cognitive disability; Intellectual disability; Court decision; Legal status; Comorbidity; Psychotic Disorders 


\section{Severity of cognitive disability and Mental Health Court determinations about fitness to stand trial}

\section{INTRODUCTION}

Cognitive disability is an umbrella term used to describe a range of conditions, including acquired brain injury and intellectual, developmental and neurological conditions (Birgden 2016), which manifest in significant impairment in intellectual and/or adaptive functioning in social, practical or conceptual domains (Tassé et al. 2012). Thus, the ascertainment of severity of cognitive impairment now extends beyond traditional measures of intellectual functioning such as the widely-used Intelligence Quotient (IQ) test (Siegel 1989). Cognitive disability has no criterion for age of onset of impairment, which distinguishes it from intellectual disability (American Psychiatric Association 2013, Braddock et al. 2004). Although co-occurring cognitive impairment is common (McCarthy et al. 2015), developmental disorders such as Autism Spectrum Disorder (ASD) and Foetal Alcohol Spectrum Disorder (FASD), and acquired brain injury may not result in significant cognitive impairment (King \& Murphy 2014, Streissguth et al. 1991, Williams et al. 2010).

The prevalence of cognitive disability in the criminal justice system remains a source of debate. Systematic reviews restricted to conservative diagnostic criteria have concluded that intellectual disability and ASD are not overrepresented in the criminal justice system (King \& Murphy 2014, Fazel et al. 2008). However, prevalence estimates based on validated screening tools suggest that intellectual disability (Dias et al. 2013); developmental disabilities such as ASD (Ashworth 2016, Scragg \& Shah 1994) and FASD (Popova et al. 2011); and acquired brain injury (Williams et al. 2010) may be overrepresented in the criminal justice system. This increased screening prevalence of cognitive disability has been observed throughout the criminal justice system including juvenile detention (Haysom et al. 2014), police custody (McKinnon et al. 2015), pre-trial detention (Crocker et al. 2007), adult correctional facilities (Dias et al. 2013) and the probation environment (Mason \& Murphy 2002). 
Individuals with cognitive disability in the criminal justice system often have multiple comorbidities with complex health-related and social needs (Baldry et al. 2013). A syndemic framework for understanding the complex interaction between individual (e.g., gender, Indigenous status) and structural factors (e.g., generational disadvantage) experienced by people with cognitive disability who come in contact with the criminal justice system has recently been explored (Claudio et al. 2017). Prior research has asserted that increased social disadvantage experienced by Indigenous people in the community can compound cognitive impairment and vulnerability for Indigenous people in the criminal justice system (Baldry et al. 2015). Compared to their non-Indigenous counterparts, Indigenous women in custody have increased history of trauma and comorbid mental health disorders (Heffernan et al. 2015), which may further complicate the identification and management of cognitive impairment.

The experience of cognitive disability presents unique vulnerabilities at multiple stages throughout the criminal justice system (Hepner et al. 2015). During police interviews, when complex language is used and/or leading questions are posed, people with cognitive disability are more likely to provide an erroneous account of events, and in particular, an account that might be seen to 'please' the interviewer (Clare \& Gudjonsson 1995). Cognitive disability may limit active and effective participation in the trial process such as the ability to plead, instruct counsel, or respond to cross examination (Baroff et al. 2004). People with cognitive disability are more likely to be manipulated and assaulted in prison compared with their counterparts without cognitive disability (Freeman 2012). Finally, people with cognitive disability may experience greater challenges adhering to the requirements of sentencing in the community and parole conditions on prison release (Baldry 2014, Murphy et al. 2017). Individuals who are newly sentenced or recently released on parole must rapidly learn and adhere to a new set of rules, obligations and expectations such as attendance at community corrections appointments, avoidance of contact with particular persons or places, and curfews imposed by the court. Cognitive disability can impede the learning of, and consistent 
compliance with a new and abstract set of rules (Mason \& Murphy 2002). Without appropriate support and assistance, challenges in literacy, comprehension, reasoning, motor function, and interpreting rules and social norms compound disadvantage for people with cognitive disability in the criminal justice system (Baldry et al. 2013). Prior research has observed that people with cognitive disability have an increased risk of false confession, conviction, and longer prison sentences compared to people without cognitive disability (Petersilia 2000). These vulnerabilities in the criminal justice system have been considered in the legal contexts of soundness of mind (at the time of the offence) and fitness for trial.

Soundness of mind is a critical consideration in determining culpability, and is based in the criminal law requirement to prove both actus reaus (the alleged act was indeed perpetrated) and mens rea (the perpetrator was knowingly culpable, by act or omission). Derived from the common law insanity defence, the test of soundness is essentially a test of culpability (or mens rea) and considers not only knowledge of 'right and wrong' but the ability to resist impulsivity (Baroff et al. 2004). Although initially developed as a legal test of acute psychiatric impairment due to severe mental illness (Scott 2011), many jurisdictions such as Canada, United States, England, Wales, Scotland, Germany, The Netherlands, France, New Zealand, and all States and Territories of Australia have included specific provisions for, or broadened the interpretation of existing legislation to include, determinations of unsoundness due to cognitive impairment (Desmarais et al. 2008, Allnutt et al. 2007, Resnick \& Noffsinger 2004, Victorian Law Reform Commission 2014). While basic moral reasoning is possessed by most people with cognitive disability (Langdon et al. 2011), and the majority of individuals with a cognitive disability possess the ability to meet criteria for culpability at the time of offence (Lambrick \& Glaser 2004), there are some who lack the capacity to understand legal processes and rights. Severity of impairment has been asserted as a key determinant of competency to stand trial; as impairment symptoms become more severe, often the ability to reason, comprehend facts, and interact effectively with legal counsel often diminishes (Brewer et al. 2016, Gay et al. 2017). 
Compared to soundness of mind, fitness for trial requires a more complex suite of cognitive skills. During the trial process, a defendant is required to understand and respond to issues that may emerge during a time of stress and confusion (Gudjonsson \& Joyce 2011) such as understanding the implication of any plea, following the nature of evidence provided by the prosecution and instructing counsel regarding cross examination (Baroff et al. 2004). Whereas the severity of cognitive impairment is likely critical in determining competence to stand trial (Sakdalan \& Egan 2014), such capacity is not static, and 'fitness' will vary according to their environment, access to appropriate clinical and social support, and the complexity of the legal decision-making required by the court case (Birgden \& Thomson 1999). Where local legislation does not prescribe tests of fitness, most Australian jurisdictions rely on R.v. Presser (1958) to inform legal decision-making. The Presser Test evaluates six critical aspects of competence to stand trial:

1. an understanding of the nature of the charges;

2. an understanding of the nature of the court proceedings;

3. the ability to challenge jurors;

4. the ability to understand the evidence;

5. the ability to decide what defence to offer; and

6. the ability to explain his or her version of the facts to counsel and the court (Australian Law Reform Commission 2014).

Although soundness and fitness are indeed legal tests, near perfect concordance between psychiatrist recommendation and court decision suggests they are most appropriately understood as 'legal tests of clinical thresholds' (Zapf et al. 2004). Both tests seek to determine the stage at which the subjective experience of psychiatric and/or cognitive impairment (the clinical threshold of severity) impacts on the ability of an individual to effectively participate in the judicial process (the legal test). Consequently, the judiciary relies heavily on clinical explanations of the subjective experience of impairment, to determine mens rea and fitness for trial (Birgden \& Thomson 1999). Often substantial deficits in verbal 
communication, a lack of close informant report, the potential for diagnostic overshadowing from comorbid severe mental illness, and the lack of standard fitness assessment guidelines for psychiatrists makes pre-trial cognitive impairment severity assessment challenging (Birgden \& Thomson 1999, White et al. 2005).

In response to these integrated clinical and legal issues, a number of Australian states have developed diversionary trial and sentencing options for those found unsound and/or unfit (Davidson 2015). Constituted by judges of the Supreme Court and advised by two psychiatrists selected from a panel, the Queensland Mental Health Court (MHC) is responsible for determinations of soundness and fitness in Queensland. An emerging area of controversy is the sentencing options available to people subject to orders emanating from determinations of unsoundness or unfitness (Australian Law Reform Commission 2016). Diversionary and sentencing options in Australia have been described in detail elsewhere (Davidson et al. 2017). In a number of Australian states including Queensland, Western Australian and the Northern Territory, a determination of unsoundness or unfitness requires sentencing to indefinite detention. Of significant concern is that indefinite orders may be made in the absence of any exploration of the facts alleged against the defendant. However, little research has been conducted on the socio-demographic, clinical and legal determinants of these orders. Therefore, we aimed to: 1) describe the severity of impairment in people with cognitive disability referred to the Queensland $\mathrm{MHC}$; 2) estimate the association between severity of impairment and a determination of unsoundness or unfitness by the MHC; and 3) assess the socio-demographic, clinical, and legal factors that predict being deemed unsound or unfit to stand trial by Court in Australia.

\section{METHODS}

\section{Participants}

Our study used routine administrative data collected by the Director of Forensic Disability, a statutory role constituted by the Queensland Forensic Disability Act 2011, on 92 individuals 
who had a criminal case referred to the Queensland MHC between 1 January 2013 and 31 December 2014 due to cognitive disability. Participants who did not receive a determination from the MHC during the study period were excluded from analysis.

\section{Measurements}

Socio-demographic information included age (18-34/ $\geq 35$ years), sex, and Indigenous status (Indigenous/non-Indigenous). The category of the primary offence and prior prison admission or pre-trial detention (yes/no) were recorded for each individual, respectively. The category of primary offence was recorded in seven broad categories according to the Australian and New Zealand Standard Offence Classification (Australian Bureau of Statistics 2011), which were then dichotomised (violent/sexual/stalking versus $\mathrm{drug} / \mathrm{motor}$ vehicle/property/other).

As part of standard practice, each individual referred to the Queensland MHC undergoes a comprehensive psychiatric and cognitive evaluation by a psychiatrist. Where feasible, other people (i.e., close informants) who may have had contact with the individual around the time of offence are consulted to provide context as to their behaviour at that time. An assessment and extensive audit of the individuals' mental health history is conducted to establish severity of cognitive impairment and comorbid mental health conditions, ascertained according to the Diagnostic and Statistical Manual of Mental Disorders, Fourth Edition, Text Revision (DSMIV-TR) criteria (American Psychiatric Association 2000). From extracted case file information, severity of cognitive impairment was collapsed dichotomously (Severe/Moderate versus Mild/Borderline). Comorbid mental health disorders were categorised into psychotic disorders, ASD and all other mental disorders and were assessed separately as dichotomous (yes/no) measures.

The primary outcomes were fit to stand trial (yes/no) and/or sound of mind at the time of the offence (yes/no) indicating the Queensland MHC judicial decision after considering the evidence presented in each case. 


\section{Statistical Analyses}

Descriptive statistics were calculated for all measures. Pearson chi-squared analysis was used to compare crude differences between MHC decision, separately for determinations of unfitness and unsoundness. The association between severity of cognitive impairment and MHC determination was estimated separately for each MHC outcome (i.e., unfitness or unsoundness), controlling for socio-demographic, clinical and legal factors. A multivariable modified Poisson regression model was fitted using robust error variance as recommended for use when the outcome investigated is rare or sufficiently common (Zou 2004). All models were adjusted for severity of cognitive impairment, age, sex, Indigenous status, comorbid psychotic disorder, ASD and other mental health disorders, category of primary offence and prior prison admission or pre-trial detention.

Missing covariate data were replaced by multiple imputation (imputed datasets: $N=100$ ) using multivariate chained equations as described previously (White et al. 2011). Monte Carlo error estimates were observed to be less than $10 \%$ of the standard error of the estimated coefficients which suggested that the number of imputations was sufficient to obtain stable multiple imputation results (White et al. 2011). Testing the potential association between missing values and all other measures indicated that the 'missing at random' assumption was likely upheld. Overall, data were imputed for 12 participants (13.6\%). Covariates imputed were prior prison admission or pre-trial detention $(n=10)$ and Indigenous status $(n=2)$, with only one covariate value imputed for each participant.

All analyses were conducted using STATA version 14.1 (StataCorp 2015). All tests of significance were two-tailed with the alpha level set at $p<0.05$.

\section{Ethical Considerations}

This study was approved by the University of Queensland Behavioural and Social Sciences Ethical Review Committee (\#2015000717) and gatekeeper approval was provided by the Queensland Government Department of Communities, Child Safety and Disability Services. 


\section{RESULTS}

Four participants (4.3\%) were excluded from analyses as they had no MHC determination during the study period. The remaining 88 participants were included in analyses.

The mean ( \pm standard deviation) age of the cohort was $34.6 \pm 12.9$ years. Males comprised the majority of the cohort $(n=76 ; 86.4 \%)$ and 17 individuals $(19.8 \%)$ identified as Indigenous Australian. A total of 39 (44.3\%) individuals referred to the MHC were assessed to have a borderline or mild severity of cognitive impairment. Eighteen (20.5\%) and 12 (13.6\%) individuals were assessed to have comorbid psychotic disorder and comorbid ASD, respectively. Over half the cohort $(55.7 \% ; n=49)$ had at least one other comorbid mental health disorder. The proportions of comorbid psychotic disorder, ASD and other mental health disorder did not differ due to severity of cognitive impairment (all $p>0.450$ ). Almost half the cohort (48.7\%; $n=38$ ) had a prior prison admission or pre-trial detention and the majority of primary offences were categorised as violent, stalking or sexual in nature $(59.1 \%$; $\mathrm{n}=52)$ (Table 1).

Overall, $30(34.1 \%)$ individuals were found unsound of mind at the time of offence and 52 (59.1\%) were found unfit to stand trial by the MHC including five individuals $(5.7 \%)$ who were found both unsound and unfit. During the study period, 11 individuals (12.5\%) were found both sound and fit by the MHC. Of the individuals assessed to have borderline/mild cognitive impairment and deemed to be sound of mind (64.1\%; $n=25), 17(68.0 \%)$ were found unfit to stand trial. Over half of the individuals assessed to have a comorbid psychotic disorder $(55.6 \% ; n=10)$ were found unsound of mind at the time of offence.

$<$ Table 1>

The association between court outcome and cohort characteristics are displayed separately for each type of $\mathrm{MHC}$ determination in Table 2. Adjusting for covariate effects, multivariable modified Poisson regression analysis with imputed values indicated that severity of cognitive impairment was positively associated with being found unfit to stand trial [adjusted 
prevalence risk ratio $(\mathrm{APRR})=1.57 ; 95 \% \mathrm{Cl}: 1.07,2.33 ; \mathrm{p}=0.023$ ] by the $\mathrm{MHC}$. Additionally, comorbid psychotic disorder predicted an increased risk of being found unsound of mind at the time of offence (APRR=3.63; $95 \% \mathrm{Cl}: 1.38,9.54 ; \mathrm{p}=0.009$ ) by the MHC. A non-significant trend between ASD and increased risk of being found unsound of mind the time of offence $(p=0.087)$ was also observed (Table 2). No other significant associations between covariate factors and MHC determination were observed.

$<$ Table 2>

\section{DISCUSSION}

\section{Severity of Cognitive Impairment}

The current study identified that over half the individuals with cognitive disability referred to the Queensland MHC had moderate or severe cognitive impairment. Furthermore, individuals with moderate/severe cognitive impairment were at 1.5 times increased likelihood of being found unfit to stand trial compared to those with mild/borderline cognitive impairment. Prior research found that increased IQ scores predicted competency to stand trial in Canada (Viljoen et al. 2002) and level of cognitive impairment predicted psychiatric recommendations of unfitness to the court in South Australia (White et al. 2012). Accordingly, our findings are highly suggestive that the clinical level of cognitive impairment is a key determinant in applying the moral, social and legal criteria required by the Presser criteria (van der Wijngaart et al. 2015, Birgden \& Thomson 1999). Therefore, diversion to the Queensland MHC offers an unprecedented opportunity to refer/divert people with prominent cognitive disabilities who have substantial vulnerabilities in the criminal justice system to appropriate social and health services.

We observed that cognitive impairment did not predict being found unsound at the time of committing the offence. Prior research has shown that people with cognitive disability may commit illegal acts as a result of social naiveté, a vulnerability to criminal exploitation, and challenges in understanding interpersonal, prosocial behaviour and good conduct norms 
(Wilson et al. 1996, Langdon et al. 2011). However, the presence of cognitive disability alone does not infer a lack of capacity and therefore culpability (Lambrick \& Glaser 2004). It should be acknowledged that due to decreased independence, substantial reliance on caregivers and a perceived lack of intent, people with severe cognitive disability rarely find themselves in the criminal justice system (Jones 2007), and are more likely to be informally diverted to the disability service system through specialist responses to 'challenging behaviour' (Holland et al. 2002).

\section{Comorbid mental health disorders}

Individuals with cognitive disability and comorbid psychotic disorders were at over three-fold increased risk of being found unsound of mind at the time of committing the offence by the MHC. Prior research has reported a large majority of schizophrenia diagnoses in determinations of unsoundness (Freiberg 1994) and psychotic symptoms have been associated with a defence of unsoundness of mind for violent offences in Australia (Spencer \& Tie 2013). Although issues of diagnostic overshadowing complicate pre-trial clinical assessment for individuals with complex comorbid disorders (White et al. 2005, Birgden \& Thomson 1999), it remains a reasonable interpretation of our findings that comorbid psychotic illness predicts determinations of unsoundness at the time of offence to a greater extent than cognitive disability alone.

Interestingly, a non-significant trend between ASD and increased risk of being found unsound of mind at the time of offence was observed. Prior research has asserted that impaired social interactions, communication deficits, limited insight into others actions, impulsivity and an obsessive pursuit of routine or preferred activities may prompt criminal acts in people with ASD without being knowingly culpable when the act is committed (Mayes 2003, Freckelton 2013). Although the overrepresentation of ASD in the criminal justice system remains a subject of some contention (Browning \& Caulfield 2011, King \& Murphy 2014), prior to contact with the criminal justice system, ASD remains undiagnosed or misdiagnosed (i.e., with psychotic disorders) in the community (Lai \& Baron-Cohen 2015). 
Additionally, ASD is often not identified and managed well in marginalised groups (Archer \& Hurley 2013). Further research examining factors that predict MHC determinations of unsoundness in people with ASD is warranted.

\section{Demographic factors}

Consistent with prior research (Sakdalan \& Egan 2014), socio-demographic determinants did not predict court outcome in the current study. It is encouraging that the static demographic factors such as Indigenous status did not predict determinations by the MHC over and above the clinical and legal factors assessed in the current study. Culturally competent court diversion has been asserted as a key component in avoiding doubly disadvantaging Indigenous individuals with a disability in contact with the justice system (Muhunthan et al. 2016). However, to assess cultural competence of MHC diversion, further research into the outcomes for Indigenous people referred to the MHCs in Australia is urgently needed.

\section{Implications for clinical practice}

The current study indicated that comorbid psychotic disorders did not predict being found unfit to stand trial independent of cognitive disability. This finding lies contrary to prior studies in the United Kingdom where psychotic symptomology has been associated with determinations of unfitness (James et al. 2001) and a majority of determinations of unfitness were due to psychotic disorders (Mackay et al. 2007). Pre-trial access to appropriate mental health care, pharmacotherapy and abstinence from alcohol and other drugs likely ameliorates psychotic symptomatology and has been asserted as pivotal in establishing fitness for trial (Mossman et al. 2007). Psychiatrists should be aware of the opportunity to assume an active role in pre-trial treatment for individuals with cognitive disability with and without co-occurring mental health disorders. Consistent with best practice guidelines from the United States (Mossman et al. 2007), improved pre-trial treatment and management of comorbid mental health disorders for individuals with cognitive disability has the potential to 
improve ascertainment of fitness and is consistent with the intent of Mental Health Act legislation in Australia.

Contact with the criminal justice system is likely to involve justice professionals who have limited disability-specific training, potentially limiting the capacity for early identification of cognitive disability in criminal justice contexts (Vanny et al. 2009). Article 13(2) of the United Nations Convention on the Rights of Persons with Disabilities (UNCRPD) demands appropriate (disability-specific) training for those working in the field of administration of justice (United Nations 2008). Prior research has asserted that forensic psychiatrists should assume a leading role in developing and providing disability-specific training to the criminal justice workforce to protect the rights of people with cognitive disability at all levels of the criminal justice system (Nedopil 2009). Such training should be developed and implemented in collaboration with community disability and health professionals, and provided to all people involved with service provision at every level of the criminal justice system. It should be evidence-informed and focussed on establishing best practice for the identification and management of cognitive disability in the criminal justice system. In addition to clinical evaluation, administering individualised, culturally-validated, and standardised screening and diagnostic measures, and to the extent available, sourcing information from close informants such as teachers, carers, friends, and family members have been asserted as best practice for the identification of cognitive disability (Luckasson \& Schalock 2015). Considerations specific to the assessment of adaptive functioning in the criminal justice system have been detailed previously (Tassé et al. 2012). Future prospective studies evaluating the effectiveness of such training are warranted.

Clinical factors predicted MHC determinations independent of socio-demographic and legal factors. Therefore, our findings highlight the importance of accurate psychiatric ascertainment of cognitive disability and severity of cognitive impairment, especially specific guidelines defining borderline cognitive disability in legal settings. Given that this complicated application of therapeutic jurisprudence, which asserts the application of law as 
an agent to change health (Kress 1999), is in its relative infancy, it is important that MHCs are subject to rigorous ongoing evaluation to establish their congruency with legal, clinical and social objectives. Currently, very little is known about the health and social outcomes for those diverted to the MHC in Australia, especially those subject to indefinite orders. A crossjurisdictional analysis of these outcomes is needed and would no doubt be informative for policy and both clinical and legal practice.

\section{Equity and Access to Justice}

Of particular interest was the observation that almost two in three individuals with mild or borderline cognitive disability were found unfit to stand trial by the MHC. Article 13 of the UNCRPD requires "effective access to justice for persons with disabilities on an equal basis with others, including through the provision of procedural and age-appropriate accommodations, in order to facilitate their effective role as direct and indirect participants...." (p. 11)(United Nations 2008). Despite this, a unique order has been reserved for people with cognitive disability where indefinite detention in the absence of the necessary standard of evidence is a likely outcome (Australian Law Reform Commission 2016). The Human Rights implications of making such orders where the defendant, although not fit for the complexity of a criminal trial may otherwise be seen as competent, and have not had the allegations against them tested to the usual threshold (i.e., beyond reasonable doubt), are potentially significant. Although most people with borderline to mild cognitive disability are deemed capable and competent to undertake many aspects of adult life with only minimal support or guidance (American Psychiatric Association 2013), there is little comparative evidence indicating fitness for trial against legal test criteria in this borderline group. Our findings raise the possibility that compared to those with a clinically significant cognitive impairment, fitness among individuals with borderline cognitive functioning may be equally compromised in a trial setting. Further research aimed at understanding the equivalence between the clinical threshold for cognitive disability and the legal test for fitness is warranted. 


\section{Limitations}

Some study limitations exist and our findings should be interpreted this context. Our findings were generated from a relatively small cohort $(\mathrm{N}<100)$ and our statistical power to detect differences should be considered when interpreting the results attained. The findings are representative of the $\mathrm{MHC}$ in only one jurisdiction in Australia which relies on the Presser test (1958) to determine fitness, thus results here may not be generalisable to jurisdictions applying other legal tests of fitness. We could not determine the contribution of psychiatric impairment severity to findings of unsoundness as there was no clinical measure of the severity of acute psychiatric impairment at the time of the offence. It was not possible to establish if effective pre-trial management of comorbid psychotic disorders was implemented prior to the assessment of cognitive impairment. We were not able to ascertain the proportion of people who had close informants that were interviewed during the clinical assessment process and thus, we could not assess the potential contribution of the presence or absence of close informant reports on court determinations of unsoundness and/or unfitness. We did not have access to transcripts of the judge's determination, therefore it is not objectively clear whether the judiciary determination was made due to cognitive or psychiatric impairment.

\section{Conclusions}

Severity of cognitive impairment is associated with determinations of unfitness but does not predict findings of unsoundness in the Queensland MHC. Comorbid psychotic disorders predict MHC determinations of unsoundness but are not associated with findings of unfitness. Psychiatrists play a pivotal role in MHC determinations for people with cognitive disability. Disability-specific training for clinicians and justice professionals at every level of the justice and MHC process is recommended to ensure the human rights of this highly vulnerable group are upheld. Further research is urgently needed examining the social and health outcomes for individuals with cognitive disability who are referred to the MHC in Australia, especially focussing on the outcomes for those on indefinite orders. 


\section{AUTHOR DISCLOSURES:}

\section{Role of Funding Source}

JY is supported by a Melbourne International Research Scholarship (PhD) from the University of Melbourne. The funding source had no additional role in the research design; data collection, analysis, or interpretation; the writing of the manuscript; or the decision to submit the article for publication.

\section{Contributors}

JY, FD, SW, KvD, KN, and NL developed the original research proposal and methodology. JY developed and conducted the statistical analysis with contributions from MV. JY wrote the initial draft manuscript with contributions from SW. JY, FD, SW, MV, KvD, KN, and NL contributed significantly to the interpretation and synthesis of results, and were involved with the development of the final manuscript submitted. JY had full access to the data used in this study and takes responsibility for the integrity of the data and accuracy of the data analysis.

\section{Conflict of Interest}

Apart from the funding resources disclosed in the acknowledgements section, the Authors declare that there is no conflict of interest.

\section{Acknowledgements}

The authors would like to acknowledge the in-kind administrative support provided by the Department of Communities, Child Safety and Disability Services. The views expressed herein are solely those of the authors, and in no way reflect the views or policies of the Director of Forensic Disability or the Queensland Government Department of Communities, Child Safety and Disability Services. 


\section{Tables and Figures}

Table 1: Queensland Mental Health Court cohort characteristics by court outcome

\begin{tabular}{|c|c|c|c|c|c|c|c|c|c|c|c|c|c|c|}
\hline \multirow[b]{2}{*}{ Characteristics } & \multicolumn{6}{|c|}{ Unfit to stand trial } & \multirow[b]{2}{*}{$p$-value ${ }^{\$}$} & \multicolumn{6}{|c|}{ Unsound of mind at the time of offence } & \multirow[b]{2}{*}{$p$-value $\$$} \\
\hline & $\mathrm{N}$ & $\begin{array}{l}\text { Unfit } \\
\mathrm{n}=52 \\
(\%) \\
\end{array}$ & $\mathrm{N}$ & $\begin{array}{l}\text { Fit } \\
n=36 \\
(\%) \\
\end{array}$ & $\mathrm{N}$ & $\begin{array}{l}\text { Total } \\
\mathrm{N}=88 \\
(\%) \\
\end{array}$ & & $\mathrm{N}$ & $\begin{array}{l}\text { Unsound } \\
\mathrm{n}=30 \\
(\%)\end{array}$ & $\mathrm{N}$ & $\begin{array}{l}\text { Sound } \\
n=58 \\
(\%) \\
\end{array}$ & $\mathrm{N}$ & $\begin{array}{l}\text { Total } \\
\mathrm{N}=88 \\
(\%) \\
\end{array}$ & \\
\hline \multicolumn{15}{|l|}{ Severity of cognitive impairment } \\
\hline Borderline/Mild & 18 & 34.6 & 21 & 58.3 & 39 & 44.3 & & 14 & 46.7 & 25 & 43.1 & 39 & 44.3 & \\
\hline Moderate/Severe & 34 & 65.4 & 15 & 41.7 & 49 & 55.7 & & 16 & 53.3 & 33 & 56.9 & 49 & 55.7 & \\
\hline Total & & & & & 88 & 100.0 & 0.028 & & & & & 88 & 100.0 & 0.750 \\
\hline \multicolumn{15}{|l|}{ Age } \\
\hline $18-34$ years & 33 & 63.5 & 21 & 58.3 & 54 & 61.4 & & 17 & 56.7 & 37 & 63.8 & 54 & 61.4 & \\
\hline$\geq 35$ years & 19 & 36.5 & 15 & 41.7 & 34 & 38.6 & & 13 & 43.3 & 21 & 36.2 & 34 & 38.6 & \\
\hline Total & & & & & 88 & 100.0 & 0.627 & & & & & 88 & 100.0 & 0.515 \\
\hline \multicolumn{15}{|l|}{ Sex } \\
\hline Female & 8 & 15.4 & 4 & 11.1 & 12 & 13.6 & & 3 & 10 & 9 & 15.5 & 12 & 13.6 & \\
\hline Male & 44 & 84.6 & 32 & 88.9 & 76 & 86.4 & & 27 & 90 & 49 & 84.5 & 76 & 86.4 & \\
\hline Total & & & & & 88 & 100.0 & 0.566 & & & & & 88 & 100.0 & 0.475 \\
\hline \multicolumn{15}{|l|}{ Indigenous status } \\
\hline Indigenous & 13 & 25.5 & 4 & 11.4 & 17 & 19.8 & & 4 & 13.8 & 13 & 22.8 & 17 & 19.8 & \\
\hline Non-Indigenous & 38 & 74.5 & 31 & 88.6 & 69 & 80.2 & & 25 & 86.2 & 44 & 77.2 & 69 & 80.2 & \\
\hline Total & & & & & 86 & 97.7 & 0.108 & & & & & 86 & 97.7 & 0.321 \\
\hline \multicolumn{15}{|l|}{ Comorbid psychotic disorder\% } \\
\hline No & 43 & 82.7 & 27 & 75.0 & 70 & 79.5 & & 20 & 66.7 & 50 & 86.2 & 70 & 79.5 & \\
\hline Yes & 9 & 17.3 & 9 & 25.0 & 18 & 20.5 & & 10 & 33.3 & 8 & 13.8 & 18 & 20.5 & \\
\hline Total & & & & & 88 & 100.0 & 0.379 & & & & & 88 & 100.0 & 0.031 \\
\hline \multicolumn{15}{|l|}{ Comorbid ASD } \\
\hline No & 46 & 88.5 & 30 & 83.3 & 76 & 86.4 & & 24 & 80 & 52 & 89.7 & 76 & 86.4 & \\
\hline Yes & 6 & 11.5 & 6 & 16.7 & 12 & 13.6 & & 6 & 20 & 6 & 10.3 & 12 & 13.6 & \\
\hline Total & & & & & 88 & 100.0 & 0.491 & & & & & 88 & 100.0 & 0.211 \\
\hline \multicolumn{15}{|l|}{$\begin{array}{l}\text { Other Comorbid Mental Health } \\
\text { Disorder§ }\end{array}$} \\
\hline No & 19 & 36.5 & 20 & 55.6 & 39 & 44.3 & & 15 & 50 & 24 & 41.4 & 39 & 44.3 & \\
\hline Yes & 33 & 63.5 & 16 & 44.4 & 49 & 55.7 & & 15 & 50 & 34 & 58.6 & 49 & 55.7 & \\
\hline Total & & & & & 88 & 100.0 & 0.077 & & & & & 88 & 100.0 & 0.440 \\
\hline \multicolumn{15}{|l|}{ Category of primary offence } \\
\hline Drug/Motor/Property/Other & 20 & 38.5 & 16 & 44.4 & 36 & 40.9 & & 12 & 40 & 24 & 41.4 & 36 & 40.9 & \\
\hline Violent/Sexual/Stalking & 32 & 61.5 & 20 & 55.6 & 52 & 59.1 & & 18 & 60 & 34 & 58.6 & 52 & 59.1 & \\
\hline Total & & & & & 88 & 100.0 & 0.575 & & & & & 88 & 100.0 & 0.901 \\
\hline \multicolumn{15}{|l|}{$\begin{array}{l}\text { Prior prison admission or pre-trial } \\
\text { detention }\end{array}$} \\
\hline No & 21 & 45.7 & 19 & 59.4 & 40 & 51.3 & & 14 & 51.9 & 26 & 51.0 & 40 & 51.3 & \\
\hline
\end{tabular}




\begin{tabular}{|c|c|c|c|c|c|c|c|c|c|c|c|c|c|c|}
\hline $\begin{array}{l}\text { Yes } \\
\text { Total }\end{array}$ & 25 & 54.3 & 13 & 40.6 & $\begin{array}{l}38 \\
78 \\
\end{array}$ & $\begin{array}{l}48.7 \\
88.6 \\
\end{array}$ & 0.233 & 13 & 48.1 & 25 & 49.0 & $\begin{array}{l}38 \\
78 \\
\end{array}$ & $\begin{array}{l}48.7 \\
88.6 \\
\end{array}$ & 0.942 \\
\hline
\end{tabular}

\$Pearson $\mathrm{X}^{2}$ test

\%Psychotic disorder includes schizophrenia, schizophreniform disorder, and schizoaffective disorder.

$\S$ Other Comorbid Mental Health Disorder includes substance use disorder, post-traumatic stress disorder, reactive attachment disorder, borderline personality disorder, anxiety

disorder, epilepsy, attention deficit hyperactivity disorder, dementia, depression, oppositional defiant disorder, impulse control disorder, bipolar disorder, and antisocial personality disorder. 
Table 2 - Association between court outcome and cohort characteristics.

\begin{tabular}{|c|c|c|c|c|c|c|c|c|}
\hline \multirow[b]{2}{*}{ Characteristic } & \multicolumn{3}{|c|}{ Unfit to stand trial } & \multicolumn{5}{|c|}{ Unsound of mind at the time of offence } \\
\hline & $\begin{array}{r}\text { Crude PRR } \\
(95 \% \mathrm{CI})\end{array}$ & $\begin{array}{r}\text { Adjusted PRR } \\
(95 \% \mathrm{Cl})\end{array}$ & $\begin{array}{r}\text { Adjusted PRR } \\
\text { with imputed } \\
\text { values\% } \\
(95 \% \mathrm{Cl})\end{array}$ & $\begin{array}{r}\mathrm{p}- \\
\text { value }^{\$, \%}\end{array}$ & $\begin{array}{r}\text { Crude OR } \\
(95 \% \mathrm{Cl})\end{array}$ & $\begin{array}{r}\text { Adjusted PRR } \\
(95 \% \mathrm{Cl})\end{array}$ & $\begin{array}{r}\text { Adjusted PRR } \\
\text { with imputed } \\
\text { values } \% \\
(95 \% \mathrm{Cl})\end{array}$ & $\begin{array}{r}\mathrm{p}- \\
\text { value }^{\$, \%}\end{array}$ \\
\hline \multicolumn{9}{|l|}{$\begin{array}{l}\text { Severity of cognitive } \\
\text { impairment }\end{array}$} \\
\hline Borderline/Mild & 1 & 1 & 1 & & 1 & 1 & 1 & \\
\hline Moderate/Severe & $1.50(1.02,2.22)$ & $1.78(1.15,2.74)$ & $1.57(1.07,2.33)$ & 0.023 & $0.91(0.51,1.63)$ & $0.79(0.43,1.44)$ & $0.84(0.48,1.47)$ & 0.534 \\
\hline \multicolumn{9}{|l|}{ Age } \\
\hline 18-34 years & 1 & 1 & 1 & & 1 & 1 & 1 & \\
\hline$\geq 35$ years & $0.91(0.63,1.32)$ & $0.91(0.62,1.35)$ & $0.85(0.58,1.23)$ & 0.391 & $1.21(0.68,2.18)$ & $1.50(0.81,2.77)$ & $1.54(0.85,2.78)$ & 0.155 \\
\hline \multicolumn{9}{|l|}{ Sex } \\
\hline Female & 1 & 1 & 1 & & 1 & 1 & 1 & \\
\hline Male & $0.87(0.56,1.36)$ & $0.79(0.51,1.22)$ & $0.77(0.51,1.17)$ & 0.286 & $1.42(0.51,3.99)$ & $1.55(0.61,3.96)$ & $1.68(0.69,4.08)$ & 0.250 \\
\hline \multicolumn{9}{|l|}{ Indigenous status } \\
\hline Indigenous & 1 & 1 & 1 & & 1 & 1 & 1 & \\
\hline Non-Indigenous & $0.72(0.51,1.01)$ & $0.70(0.48,1.04)$ & $0.81(0.55,1.20)$ & 0.301 & $1.54(0.62,3.86)$ & $1.92(0.55,6.76)$ & $1.24(0.48,3.20)$ & 0.662 \\
\hline \multicolumn{9}{|l|}{ Comorbid psychotic disorder $\$$} \\
\hline No & 1 & 1 & 1 & & 1 & 1 & 1 & \\
\hline Yes & $0.81(0.49,1.34)$ & $0.77(0.46,1.29)$ & $0.67(0.38,1.18)$ & 0.163 & $1.94(1.11,3.40)$ & $3.35(1.14,9.77)$ & $3.63(1.38,9.54)$ & 0.009 \\
\hline \multicolumn{9}{|l|}{ Comorbid ASD } \\
\hline No & 1 & 1 & 1 & & 1 & 1 & 1 & \\
\hline Yes & $0.83(0.45,1.50)$ & $0.82(0.47,1.43)$ & $0.80(0.46,1.37)$ & 0.412 & $1.58(0.82,3.06)$ & $1.79(0.78,4.12)$ & $1.98(0.91,4.33)$ & 0.087 \\
\hline \multicolumn{9}{|l|}{$\begin{array}{l}\text { Other Comorbid Mental Health } \\
\text { Disorder§§ }\end{array}$} \\
\hline No & 1 & 1 & 1 & & 1 & 1 & 1 & \\
\hline Yes & $1.38(0.95,2.02)$ & $1.18(0.74,1.54)$ & $1.21(0.80,1.83)$ & 0.370 & $0.80(0.44,1.42)$ & $1.12(0.59,2.11)$ & $1.07(0.60,1.92)$ & 0.823 \\
\hline \multicolumn{9}{|l|}{ Category of primary offence } \\
\hline Drug/Motor/Property/Other & 1 & 1 & 1 & & 1 & 1 & 1 & \\
\hline Violent/Sexual/Stalking & $1.11(0.77,1.60)$ & $1.06(0.74,1.54)$ & $1.12(0.78,1.62)$ & 0.529 & $1.04(0.57,1.89)$ & $1.27(0.66,2.46)$ & $1.06(0.57,1.95)$ & 0.856 \\
\hline $\begin{array}{l}\text { Prior prison admission or pre- } \\
\text { trial detention }\end{array}$ & & & & & & & & \\
\hline No & 1 & 1 & 1 & & 1 & 1 & 1 & \\
\hline Yes & $1.25(0.86,1.82)$ & $1.34(0.87,2.07)$ & $1.29(0.84,2.00)$ & 0.244 & $0.98(0.53,1.81)$ & $0.51(0.17,1.54)$ & $0.55(0.20,1.50)$ & 0.242 \\
\hline
\end{tabular}

ASD: Autism Spectrum Disorder; PRR: Prevalence Risk Ratio; 95\% Cl: 95\% Confidence Interval

\$adjusted for severity of cognitive impairment, age, sex, Indigenous status, comorbid psychotic disorder, comorbid ASD, other comorbid mental health disorders, category of offence, and prior prison admission or pre-trial detentions.

$\%$ Missing covariate values $(\mathrm{X} \% ; \mathrm{N}=12)$ replaced using multiple imputation. Covariates imputed were prior prison admission or pre-trial detention ( $\mathrm{n}=10)$ and Indigenous status $(n=2)$. 
§sychotic disorder includes schizophrenia, schizophreniform disorder, and schizoaffective disorder.

\&Other Comorbid Mental Health Disorder includes substance use disorder, post-traumatic stress disorder, reactive attachment disorder, borderline personality disorder,

anxiety disorder, epilepsy, attention deficit hyperactivity disorder, dementia, depression, oppositional defiant disorder, impulse control disorder, bipolar disorder, and antisocial personality disorder. 


\section{REFERENCES}

Allnutt, S., Samuels, A. \& O'Driscoll, C. (2007) The Insanity Defence: From wild Beasts to M'Naghten. Australasian Psychiatry, 15, 292-298. doi:10.1080/10398560701352181

American Psychiatric Association (2000) Diagnostic and Statistical Manual of Mental Disorders, Fourth Edition, Text Revision., (Trans. American Psychiatric Association, Washington, DC.

American Psychiatric Association (2013) Diagnostic and Statistical Manual of Mental Disorders, Fifth Edition, (Trans. American Psychiatric Association, Arlington, VA.

Archer, N. \& Hurley, E. A. (2013) A justice system failing the autistic community. Journal of Intellectual Disabilities and Offending Behaviour, 4, 53-59. doi:doi:10.1108/JIDOB02-2013-0003

Ashworth, S. (2016) Autism is underdiagnosed in prisoners. BMJ, 353. doi:10.1136/bmj.i3028

Australian Bureau of Statistics (2011) Australian and New Zealand Standard Offence Classification (ANZSOC). Cat no. 1234.0. ABS, Canberra.

Australian Law Reform Commission (2014) Equality, Capacity and Disability in Commonwealth Laws. ALRC Report 124. Australian Government, Canberra

Australian Law Reform Commission (2016) ALRC submission: Inquiry into the indefinite detention of people with cognitive and psychiatric impairment in Australia. Australian Government, Canberra.

Baldry, E. (2014) Disability at the margins: limits of the law. Griffith Law Review, 23, 370388. doi:10.1080/10383441.2014.1000218

Baldry, E., Clarence, M., Dowse, L. \& Trollor, J. (2013) Reducing Vulnerability to Harm in Adults With Cognitive Disabilities in the Australian Criminal Justice System. Journal of Policy and Practice in Intellectual Disabilities, 10, 222-229. doi:10.1111/jppi.12039

Baldry, E., McCausland, R., Dowse, L. \& McEntyre, E. (2015) A predictable and preventable path: Aboriginal people with mental and cognitive disabilities in the criminal justice system. UNSW, Sydney, Australia.

Baroff, G. S., Gunn, M. \& Hayes, S. (2004) Legal issues. In: Offenders with developmental disabilities (eds W. R. Lindsay, J. L. Taylor \& P. Sturmley). pp. 37-66. John Wiley \& Sons Ltd, London.

Birgden, A. (2016) Enabling the disabled: A proposed framework to reduce discrimination against forensic disability clients requiring access to programs in prison. Mitchell Hamline L. Rev., 42, 637-684.

Birgden, A. \& Thomson, D. (1999) The assessment of fitness to stand trial for defendants with an intellectual disability: A proposed assessment procedure involving mental health professionals and lawyers. Psychiatry, Psychology and Law, 6, 207-214. doi:10.1080/13218719909524963

Braddock, D., Rizzolo, M. C., Thompson, M. \& Bell, R. (2004) Emerging Technologies and Cognitive Disability. Journal of Special Education Technology, 19, 49-56. doi:10.1177/016264340401900406

Brewer, R. J., Davies, G. M. \& Blackwood, N. J. (2016) Fitness to Plead: The Impact of Autism Spectrum Disorder. Journal of Forensic Psychology Practice, 16, 182-197. doi:10.1080/15228932.2016.1177285

Browning, A. \& Caulfield, L. (2011) The prevalence and treatment of people with Asperger's Syndrome in the criminal justice system. Criminology and Criminal Justice, 11, 165180. doi:10.1177/1748895811398455

Clare, I. C. H. \& Gudjonsson, G. H. (1995) The vulnerability of suspects with intellectual disabilities during police interviews: A review and experimental study of decisionmaking. Mental Handicap Research, 8, 110-128. doi:10.1111/j.14683148.1995.tb00149.x

Claudio, F., van Dooren, K., Young, J. \& Lennox, N. (2017) Stigma Syndemic among People with Intellectual Disability Who Have Been Incarcerated. In: Stigma Syndemics: New 
Directions in Biosocial Health (eds B. Ostrach, S. Lerman \& M. Singer). Lexington Books, London.

Crocker, A. G., Côté, G., Toupin, J. \& St-Onge, B. (2007) Rate and characteristics of men with an intellectual disability in pre-trial detention. Journal of Intellectual and Developmental Disability, 32, 143-152. doi:10.1080/13668250701314053

Davidson, F. (2015) Mental Health Liaison and Diversion: Court Liaison Services and Mental Health Court Programs in Australia. The Australian Centre for Research Excellence in Offender Health, Brisbane.

Davidson, F., Heffernan, E., Greenberg, D., Waterworth, R. \& Burgess, P. (2017) Mental Health and Criminal Charges: Variation in Diversion Pathways in Australia. Psychiatry, Psychology and Law, 1-11. doi:10.1080/13218719.2017.1327305

Desmarais, S. L., Hucker, S., Brink, J. \& De Freitas, K. (2008) A Canadian Example of Insanity Defence Reform: Accused Found Not Criminally Responsible Before and After the Winko Decision. International Journal of Forensic Mental Health, 7, 1-14. doi:10.1080/14999013.2008.9914399

Dias, S., Ware, R. S., Kinner, S. A. \& Lennox, N. G. (2013) Co-occurring mental disorder and intellectual disability in a large sample of Australian prisoners. Australian and New Zealand Journal of Psychiatry, 47, 938-944. doi:10.1177/0004867413492220

Fazel, S., Xenitidis, K. \& Powell, J. (2008) The prevalence of intellectual disabilities among 12000 prisoners - A systematic review. International Journal of Law and Psychiatry, 31, 369-373. doi:10.1016/j.ijlp.2008.06.001

Freckelton, I. (2013) Autism Spectrum Disorder: Forensic Issues and Challenges for Mental Health Professionals and Courts. Journal of Applied Research in Intellectual Disabilities, 26, 420-434. doi:10.1111/jar.12036

Freeman, J. (2012) The relationship between lower intelligence, crime and custodial outcomes: a brief literary review of a vulnerable group. Vulnerable Groups \& Inclusion. doi:10.3402/vgi.v3i0.14834

Freiberg, A. (1994) The disposition of mentally disordered offenders in Australia: 'Out of mind, out of sight' revisited. Psychiatry, Psychology and Law, 1, 97-118. doi:10.1080/13218719409524834

Gay, J. G., Vitacco, M. J. \& Ragatz, L. (2017) Mental health symptoms predict competency to stand trial and competency restoration success. Legal and Criminological Psychology, 22, 288-301. doi:10.1111/lcrp.12100

Gudjonsson, G. \& Joyce, T. (2011) Interviewing adults with intellectual disabilities. Advances in Mental Health and Intellectual Disabilities, 5, 16-21. doi:10.5042/amhid.2011.0108

Haysom, L., Indig, D., Moore, E. \& Gaskin, C. (2014) Intellectual disability in young people in custody in New South Wales, Australia - prevalence and markers. Journal of Intellectual Disability Research, 58, 1004-1014. doi:10.1111/jir.12109

Heffernan, E., Andersen, K., Davidson, F. \& Kinner, S. A. (2015) PTSD Among Aboriginal and Torres Strait Islander People in Custody in Australia: Prevalence and Correlates. Journal of Traumatic Stress, 28, 523-530. doi:10.1002/jts.22051

Hepner, I., Woodward, M. N. \& Stewart, J. (2015) Giving the Vulnerable a Voice in the Criminal Justice System: The Use of Intermediaries With Individuals With Intellectual Disability. Psychiatry, Psychology and Law, 22, 453-464. doi:10.1080/13218719.2014.960032

Holland, T., Clare, I. C. H. \& Mukhopadhyay, T. (2002) Prevalence of 'criminal offending' by men and women with intellectual disability and the characteristics of 'offenders': implications for research and service development. Journal of Intellectual Disability Research, 46, 6-20. doi:10.1046/j.1365-2788.2002.00001.x

James, D. V., Duffield, G., Blizard, R. \& Hamilton, L. W. (2001) Fitness to plead. A prospective study of the inter-relationships between expert opinion, legal criteria and specific symptomatology. Psychological Medicine, 31, 139-150.

Jones, J. (2007) Persons With Intellectual Disabilities in the Criminal Justice System: Review of Issues. International Journal of Offender Therapy and Comparative Criminology, 51, 723-733. doi:10.1177/0306624x07299343 
King, C. \& Murphy, G. H. (2014) A Systematic Review of People with Autism Spectrum Disorder and the Criminal Justice System. Journal of Autism and Developmental Disorders, 44, 2717-2733. doi:10.1007/s10803-014-2046-5

Kress, K. (1999) Therapeutic jurisprudence and the resolution of value conflicts: what we can realistically expect, in practice, from theory. Behavioral Sciences \& the Law, 17, 555-588. doi:10.1002/(SICI)1099-0798(199923)17:5<555::AID-BSL384>3.0.CO;2-S

Lai, M.-C. \& Baron-Cohen, S. (2015) Identifying the lost generation of adults with autism spectrum conditions. The Lancet Psychiatry, 2, 1013-1027. doi:10.1016/S22150366(15)00277-1

Lambrick, F. \& Glaser, W. (2004) Sex Offenders With an Intellectual Disability. Sexual Abuse: A Journal of Research and Treatment, 16, 381-392. doi:10.1177/107906320401600409

Langdon, P. E., Murphy, G. H., Clare, I. C. H., Steverson, T. \& Palmer, E. J. (2011) Relationships Among Moral Reasoning, Empathy, and Distorted Cognitions in Men With Intellectual Disabilities and a History of Criminal Offending. American Journal on Intellectual and Developmental Disabilities, 116, 438-456. doi:10.1352/1944-7558116.6.438

Luckasson, R. \& Schalock, R. L. (2015) Standards to Guide the Use of Clinical Judgment in the Field of Intellectual Disability. Intellectual and Developmental Disabilities, 53, 240-251. doi:10.1352/1934-9556-53.3.240

Mackay, R., Mitchell, B. J. \& Howe, L. (2007) A continued upturn in unfitness to plead-more disability in relation to the trial under the 1991 Act. Criminal Law Review, 7, 530-545.

Mason, J. \& Murphy, G. (2002) Intellectual disability amongst people on probation: prevalence and outcome. Journal of Intellectual Disability Research, 46, 230-238. doi:10.1046/j.1365-2788.2002.00399.x

Mayes, T. A. (2003) Persons with autism and criminal justice: Core concepts and leading cases. Journal of Positive Behavior Interventions, 5, 92-100. doi:10.1177/10983007030050020401

McCarthy, J., Chaplin, E., Underwood, L., Forrester, A., Hayward, H., Sabet, J., Young, S., Asherson, P., Mills, R. \& Murphy, D. (2015) Characteristics of prisoners with neurodevelopmental disorders and difficulties. Journal of Intellectual Disability Research, 60, 201-206. doi:10.1111/jir.12237

McKinnon, I., Thorp, J. \& Grubin, D. (2015) Improving the detection of detainees with suspected intellectual disability in police custody. Advances in Mental Health and Intellectual Disabilities, 9, 174-185. doi:10.1108/AMHID-04-2015-0015

Mossman, D., Noffsinger, S. G., Ash, P., Frierson, R. L., Gerbasi, J., Hackett, M., Lewis, C. F., Pinals, D. A., Scott, C. L., Sieg, K. G., Wall, B. W. \& Zonana, H. V. (2007) AAPL Practice Guideline for the Forensic Psychiatric Evaluation of Competence to Stand Trial. Journal of the American Academy of Psychiatry and the Law Online, 35, S3S72.

Muhunthan, J., Eades, A.-M. \& Jan, S. (2016) UN-led Universal Periodic Review highly critical of Australia's record on human rights and health for Indigenous Australians. BMJ Global Health, 1, e000018. doi:10.1136/bmjgh-2015-000018

Murphy, G. H., Chiu, P., Triantafyllopoulou, P., Barnoux, M., Blake, E., Cooke, J., ForresterJones, R. V. E., Gore, N. J. \& Beecham, J. K. (2017) Offenders with intellectual disabilities in prison: what happens when they leave? Journal of Intellectual Disability Research, 61, 957-968. doi:10.1111/jir.12374

Nedopil, N. (2009) The role of forensic psychiatry in mental health systems in Europe. Criminal Behaviour and Mental Health, 19, 224-234. doi:10.1002/cbm.719

Petersilia, J. (2000) Doing Justice? Criminal Offenders with Developmental Disabilities. California Policy Research Center, Berkeley.

Popova, S., Lange, S., Bekmuradov, D., Mihic, A. \& Rehm, J. (2011) Fetal alcohol spectrum disorder prevalence estimates in correctional systems: A systematic literature review. Can J Public Health, 102, 336-340. 
Resnick, P. J. \& Noffsinger, S. (2004) Competency to Stand Trial and the Insanity Defense. In: Textbook of Forensic Psychiatry (eds R. I. Simon \& L. H. Gold). American Psychiatric Publishing, Inc., Washington, DC.

Sakdalan, J. A. \& Egan, V. (2014) Fitness to Stand Trial in New Zealand: Different Factors Associated with Fitness to Stand Trial Between Mentally Disordered and Intellectually Disabled Defendants in the New Zealand Criminal Justice System. Psychiatry, Psychology and Law, 21, 658-668. doi:10.1080/13218719.2014.910857

Scott, R. (2011) Crimes (Mental Impairment and Fitness for Trial) Act (Victoria) R v Fitchett [2009] VSCA 150 Buchanan, Vincent and Ashley JJA. Psychiatry, Psychology and Law, 18, 1-14. doi:10.1080/13218719.2010.521126

Scragg, P. \& Shah, A. (1994) Prevalence of Asperger's syndrome in a secure hospital. The British Journal of Psychiatry, 165, 679-682. doi:10.1192/bjp.165.5.679

Siegel, L. S. (1989) IQ Is Irrelevant to the Definition of Learning Disabilities. Journal of Learning Disabilities, 22, 469-478. doi:10.1177/002221948902200803

Spencer, J. \& Tie, A. (2013) Psychiatric symptoms associated with the mental health defence for serious violent offences in Queensland. Australasian Psychiatry, 21, 147152. doi:10.1177/1039856212470501

StataCorp (2015) Stata Statistical Software: Release 14. StataCorp LP, College Station, TX.

Streissguth, A., Aase, J. M., Clarren, S. K., Randels, S. P., LaDue, R. A. \& Smith, D. F. (1991) Fetal alcohol syndrome in adolescents and adults. JAMA, 265, 1961-1967. doi:10.1001/jama.1991.03460150065025

Tassé, M. J., Schalock, R. L., Balboni, G., Bersani Jr, H., Borthwick-Duffy, S. A., Spreat, S., Thissen, D., Widaman, K. F. \& Zhang, D. (2012) The Construct of Adaptive Behavior: Its Conceptualization, Measurement, and Use in the Field of Intellectual Disability. American Journal on Intellectual and Developmental Disabilities, 117, 291-303. doi:10.1352/1944-7558-117.4.291

United Nations (2008) Convention on the Rights of Persons with Disabilities United Nations, Geneva.

van der Wijngaart, S., Hawkins, R. \& Golus, P. (2015) The Role of Psychologists in the South Australian Fitness to Stand Trial Process. Psychiatry, Psychology and Law, 22, 75-93. doi:10.1080/13218719.2014.919626

Vanny, K. A., Levy, M. H., Greenberg, D. M. \& Hayes, S. C. (2009) Mental illness and intellectual disability in Magistrates Courts in New South Wales, Australia. Journal of Intellectual Disability Research, 53, 289-297. doi:10.1111/j.1365-2788.2008.01148.x

Victorian Law Reform Commission (2014) Review of the Crimes (Mental Impairment and Unfitness to be Tried) Act 1997. Victorian Law Reform Commission, Melbourne.

Viljoen, J. L., Roesch, R. \& Zapf, P. A. (2002) An Examination of the Relationship between Competency to Stand Trial, Competency to Waive Interrogation Rights, and Psychopathology. Law and Human Behavior, 26, 481-506.

White, A. J., Batchelor, J., Pulman, S. \& Howard, D. (2012) The Role of Cognitive Assessment in Determining Fitness to Stand Trial. International Journal of Forensic Mental Health, 11, 102-109. doi:10.1080/14999013.2012.688091

White, I. R., Royston, P. \& Wood, A. M. (2011) Multiple imputation using chained equations: Issues and guidance for practice. Statistics in Medicine, 30, 377-399. doi:10.1002/sim.4067

White, P., Chant, D., Edwards, N., Townsend, C. \& Waghorn, G. (2005) Prevalence of Intellectual Disability and Comorbid Mental Illness in an Australian Community Sample. Australian and New Zealand Journal of Psychiatry, 39, 395-400. doi:10.1080/j.1440-1614.2005.01587.x

Williams, W. H., Mewse, A. J., Tonks, J., Mills, S., Burgess, C. N. W. \& Cordan, G. (2010) Traumatic brain injury in a prison population: prevalence and risk for re-offending. Brain Injury, 24, 1184-1188. doi:10.3109/02699052.2010.495697

Wilson, C., Seaman, L. \& Nettelbeck, T. (1996) Vulnerability to criminal exploitation: influence of interpersonal competence differences among people with mental 
retardation. Journal of Intellectual Disability Research, 40, 8-16. doi:10.1111/j.13652788.1996.tb00597.x

Zapf, P. A., Hubbard, K. L., Cooper, V. G., Wheeles, M. C. \& Ronan, K. A. (2004) Have the Courts Abdicated Their Responsibility for Determination of Competency to Stand Trial to Clinicians? Journal of Forensic Psychology Practice, 4, 27-44. doi:10.1300/J158v04n01_02

Zou, G. (2004) A Modified Poisson Regression Approach to Prospective Studies with Binary Data. American Journal of Epidemiology, 159, 702-706. doi:10.1093/aje/kwh090 